\title{
JUURNAL_RU
}

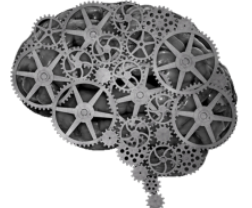

COMPANY GROUP "INTELLEKT"

\author{
Федина Л.М. \\ Волгоградская академия МВД России \\ Волгоград, Россия
}

doi: 10.18411/1j2016-5-3-19

\section{Сотрудничество сторон государственного контракта на поставку товаров, как необходимое условие исполнения обязательства}

Как следует из теории гражданского права, исполнение обязательства это самый желательный способ его прекращения. И если исходить из того, что контракт на поставку товаров для государственных нужд является обоснованным результатом проявления субъектами правоотношений своей воли, направленной на заключение именно данного вида договора и на условиях, предусмотренных в нем,[1] то исполнение такого обязательства будет означать, что оно завершается именно так, как это было предусмотрено не только законом, но и согласованной волей сторон.Однако обязательство должно быть не просто исполненным, а соответствовать гражданско-правовыми принципам исполнения обязательства (принцип добросовестного, реального исполнения обязательства и т.д.). Важнейшим из данных принципов традиционно считается надлежащее исполнение, которое предполагает исполнение обязательства надлежащими субъектами, надлежащим предметом, надлежащим способом, в надлежащем месте, в надлежащий срок[2]. С целью стимулирования сторон обязательства к подобному исполнению, предусмотрен ряд мер, в том числе дополнительного имущественного воздействия, называемых способами обеспечения исполнения обязательства. Сущность таких способов сводится к предоставлению кредитору дополнительного обеспечения в виде определенного эквивалента, сделанного им предоставления. Правовая дискуссия о степени 
эффективности способов обеспечения исполнения обязательств, и выявление наиболее действенного и практически применяемого, из поименованных в законе, продолжается по сей день.

При этом нельзя оставить без внимания тот факт, что самое желательное состояние правоотношений, складывающихся в сфере поставки товаров, будет существовать тогда, когда способы обеспечения обязательств так и останутся превентивной мерой, и стороны не будут прибегать к их использованию, надлежаще исполняя условия контракта. Такое исполнение подразумевает не только действия поставщика в интересах государственного заказчика, но и взаимные положительные действия последнего, который должен не только исполнить свои обязанности по договору, но и содействовать надлежащему исполнению другой стороны, поскольку удовлетворение его имущественного интереса и есть первейшая цель вступления в данные правоотношения. Сотрудничество между сторонами обязательства носит не просто рекомендательный характер, но и закреплено в качестве принципа международных коммерческих договоров унификации частного права (УНИДРУА). Также данный источник права декларирует, что «договор представляется не просто точкой, где сходятся противоречивые интересы, он также должен в определенной степени рассматриваться и как общий проект, в котором каждая сторона должна сотрудничать»[3]. То есть, проецируя такое положение на правоотношения, возникающие из государственного контракта на поставку товаров, можно сказать, что сторонам необходимо в ходе исполнения достигнуть наиболее плотного сотрудничества сцелью недопущения даже незначительного отклонения от условий контракта, особенно это будет касаться договорных отношений долгосрочного характера, когда выполнение поставщиком своих обязанностей осуществляется путем многократных отгрузок отдельных партий товаров в соответствующие периоды поставки.

При этом, в соответствии с законодательством о контрактной системе[4], даже не значительное изменение условий государственного контракта за 
пределами, установленными законом, чревато для обеих сторон, поскольку отчет об исполнении каждого обязательства на поставку товаров для государственных нужд (за исключением случаев, прямо предусмотренных законом) выставляется в единой информационной сети по окончании правоотношений. В случае не достижения взаимопонимания и возникновения трудностей при исполнении хотя бы у одной из сторон контракта, последствия видятся не только в применении санкций к виновному участнику, но и неудовлетворенный, или не полностью удовлетворенный интерес государственного заказчика, что умоляет эффективность всех предыдущих этапов правоотношения.

В подтверждение нашего мнения об особой роли сотрудничества между сторонами правоотношения возникающего из государственного контракта на поставку товаров, укажем, что законодатель в п.2 ст.24 Федерального закона о контрактной системе выделяет в качестве одной из обязанностей поставщика «своевременно предоставлять достоверную информацию о ходе исполнения своих обязательств, в том числе о сложностях, возникающих при исполнении контракта». Таким образом, только добросовестное сотрудничество сторон обязательства может гарантировать его надлежащее исполнение, удовлетворяющее обоюдные интересы. 


\section{Литература}

1. Гапанович А.В. Реализация принципа свободы договора в Законе о размещении заказов // Наука и современность-2010: Сборник материалов II Международной научно-практической конференции: В 3 х ч. / Под ред. С.С. Чернова. Новосибирск: СИБПРИНТ, 2010. Ч. 3. С. 303.

2. Гапанович А.В. Особенности исполнения обязательств по государственному (муниципальному) контракту// Право и экономика. 2013.№2.

3. Принципы международных коммерческих договоров УНИДРУА 2010. М.:Статут, 2013, стр.118.

4. Федеральный закон от 05.04.2013 № 44-Ф3 «О контрактной системе в сфере закупок товаров, работ, услуг для обеспечения государственных и муниципальных нужд». Собрание законодательства РФ, 08.04.2013, №14, ст. 1652. 